CLINICAL STUDY

\title{
Associations of IGF 1 and its binding proteins with abdominal aortic aneurysm and aortic diameter in older men
}

\author{
Bu B Yeap ${ }^{1,2}$, S A Paul Chubb ${ }^{1,3}$, Kieran A McCaul ${ }^{4}$, Leon Flicker ${ }^{1,4}$, Ken K Y Ho ${ }^{5}$, Jonathan Golledge ${ }^{6}$, \\ Graeme J Hankey ${ }^{1}$ and Paul E Norman ${ }^{7}$ \\ ${ }^{1}$ School of Medicine and Pharmacology, University of Western Australia, Perth, Western Australia, Australia, ${ }^{2}$ Department of Endocrinology and Diabetes \\ and ${ }^{3}$ PathWest Laboratory Medicine, Fremantle Hospital, Fremantle, Western Australia, Australia, ${ }^{4}$ WA Centre for Health and Ageing, Centre for Medical \\ Research, University of Western Australia, Perth, Western Australia, Australia, ${ }^{5}$ Centres for Health Research, Princess Alexandra Hospital, Brisbane, \\ Queensland, Australia, ${ }^{6}$ Vascular Biology Unit, School of Medicine, James Cook University, Townsville, Queensland, Australia and ${ }^{7}$ School of Surgery, \\ University of Western Australia, Perth, Western Australia, Australia
}

(Correspondence should be addressed to B B Yeap who is now at School of Medicine and Pharmacology, Level 2, T Block, Fremantle Hospital, Alma Street, Fremantle, Western Australia 6160, Australia; Email: byeap@cyllene.uwa.edu.au)

\begin{abstract}
Objective: Abdominal aortic aneurysm (AAA) is most prevalent in older men. GH secretion declines with age resulting in reduced IGF1 levels. IGF1 and its binding proteins (IGFBPs) are expressed in vasculature, and lower IGF1 levels have been associated with cardiovascular risk factors and disease. However, the relationship of the IGF1 system with aortic dilation and AAA is unclear. We tested the hypothesis that circulating IGF1 and IGFBPs are associated with AAA and aortic diameter in older men.

Design: A cross-sectional analysis involving 3981 community-dwelling men aged 70-89 years was performed.

Methods: Abdominal aortic diameter was measured by ultrasound. Plasma total IGF1, IGFBP1 and IGFBP3 were measured by immunoassays.

Results: After adjustment for age, body mass index, waist:hip ratio, smoking, hypertension, dyslipidemia, diabetes, coronary heart disease and serum creatinine, a higher IGF1 level was associated with AAA (odds ratio $(\mathrm{OR}) / 1$ s.D. increase $1.18,95 \%$ confidence interval $(\mathrm{CI}) 1.05-1.33, P=0.006)$, as was the ratio of IGF1/IGFBP3 $(\mathrm{OR}=1.22,95 \% \mathrm{CI} 1.10-1.35, P<0.001)$. Highest IGF1 concentrations compared with lowest quintile were significantly associated with AAA (quintile $(Q) 5$ vs Q1: OR $=1.80,95 \%$ CI 1.20 $2.70, P=0.004$ ) as were IGF1/IGFBP3 ratios (Q5 vs Q1: OR $=2.52,95 \%$ CI $1.59-4.02, P<0.001)$. IGF1 and IGFBP1 were independently associated with aortic diameter $(\beta=0.200$, 95\% CI $0.043-0.357$, $P=0.012$ and $\beta=0.274,95 \%$ CI $0.098-0.449, P=0.002$ respectively).

Conclusions: In older men, higher IGF1 and an increased ratio of IGF1/IGFBP3 are associated with AAA, while IGFBP1 is independently associated with increased aortic diameter. Components of the IGF1 system may contribute to, or be a marker for, aortic dilation in ageing men.
\end{abstract}

European Journal of Endocrinology 166 191-197

\section{Introduction}

Ageing is associated with a decline in pituitary GH secretion, resulting in reduced liver production of insulinlike growth factor 1 (IGF1) (1). IGF1 is a pleiotropic anabolic hormone, whose bioavailability is modulated by binding with IGF-binding proteins (IGFBPs) in the circulation (2). Most circulating IGF1 is carried within a ternary complex bound with IGFBP 3 and the acid-labile subunit. IGFBP1 binds a smaller fraction of plasma IGF1, but does so in response to metabolic stimuli (3). Insulin suppresses hepatic IGFBP1 synthesis, decreasing the amount available for binding IGF1 and accounting for the association of reduced IGFBP1 with insulin resistance or the metabolic syndrome (4).

Abdominal aortic aneurysm (AAA) resulting from dilation of the abdominal aorta is a predictor of mortality from aortic rupture and other manifestations of cardiovascular disease (CVD) $(5,6)$. Aortic diameter is a marker of global cardiovascular risk even in the absence of an AAA. Increasing age and male gender are key risk factors for AAA (7). IGF1, IGF1 receptors and IGFBPs are expressed in vascular smooth muscle cells (VSMC) of human atherosclerotic plaques (8), and lower circulating levels of IGF1 have been associated with the incidence of cardiovascular events and stroke in previous studies $(9,10)$. IGF1 concentration was reported to be decreased in human AAA tissue while concentrations of IGFBP1 and IGFBP 3 were increased, raising the possibility that the IGF1 system contributes to the pathophysiology of AAA (11). However, an association between IGF1 status and the increased prevalence of AAA has never been examined in older men. 
A reduced ratio of IGF1/IGFBP3 that may reflect a lower proportion of free or unbound IGF1 has been associated with metabolic syndrome (12). Therefore, we investigated the associations of plasma total IGF1, IGFBP1, IGFBP 3 and the ratio of IGF1/IGFBP3 with AAA and aortic diameter in older men.

\section{Methods}

\section{Study population}

We studied subjects in the Health In Men Study (HIMS) that consists of a cohort of men who originally participated in a randomised controlled trial of screening for AAA (13). In 1996-1999, 12203 communitydwelling men aged 65-83 years from Perth, Western Australia, attended for ultrasound screening for AAA. Each man completed a questionnaire assessing aspects of history and lifestyle relevant to AAA. In 2001-2004, 4263 men from the original cohort completed a followup visit; at that time an early morning blood sample was collected. The human research ethics committee of the University of Western Australia approved the study protocol and all men gave written informed consent before entering any part of the study.

\section{Assessment of medical comorbidities}

Medical comorbidity data were collected by questionnaire in 1996-1999 and reassessed in 2001-2004. Hypertension was defined as recorded blood pressure $\geq 140 / 90$, having a diagnosis of hypertension or receiving treatment for high blood pressure. Dyslipidemia was defined as having high-density lipoprotein $<0.9 \mathrm{mmol} / \mathrm{l}$; low-density lipoprotein $\geq 3.4 \mathrm{mmol} / \mathrm{l}$; triglycerides $\geq 1.8 \mathrm{mmol} / \mathrm{l}$ or total cholesterol $\geq 5.5 \mathrm{mmol} / \mathrm{l}$, or receiving lipid-lowering therapy. Diabetes was defined as having been diagnosed with or receiving treatment for diabetes, fasting glucose level, $>7 \mathrm{mmol} / \mathrm{l}$ or non-fasting glucose, $>11.1 \mathrm{mmol} / \mathrm{l}$. Coronary heart disease (CHD) was defined by a history of myocardial infarction, angina, or treatment for coronary artery disease. Smoking history was categorised as current, ex-smoker or lifelong non-smoker. These risk factors were assessed at the time of blood sampling. Additional information on medical comorbidities was obtained from the Western Australian Data Linkage System which links together records from the Mental Health Information System, cancer register, death register and hospital morbidity data (14).

\section{Measurement of abdominal aortic diameter}

The greatest transverse and antero-posterior diameter of the infra-renal aorta was measured using a Toshiba Capasee ultrasound machine with a $3.75 \mathrm{MHz}$ probe (Toshiba Australia, North Ryde, NSW, Australia). The reproducibility of ultrasound measurements were assessed with $95 \%$ of measurement differences being $<3 \mathrm{~mm}$, as previously reported (15). An AAA was considered present when the abdominal aortic diameter was $\geq 30 \mathrm{~mm}(5,16)$.

\section{Laboratory assays}

Blood samples were collected between 0800 and $1030 \mathrm{~h}$. Plasma was prepared immediately after phlebotomy and stored at $-80{ }^{\circ} \mathrm{C}$ until assayed. Hormone assays were performed as previously described (17). Briefly, total IGF1, IGFBP1 and IGFBP3 were assayed using reagent kits of single lot numbers from Diagnostics Systems Laboratories, Inc. (DSL, supplied by Beckman Coulter, Gladesville, NSW, Australia). The total IGF1, IGFBP1 and the IGFBP3 ELISA kits were used. The assays were automated using a Grifols Triturus ELISA processor (Vital Diagnostics, Castle Hill, NSW, Australia). For measurement of total IGF1, samples were pretreated with acid to displace IGF1 from binding proteins, followed by neutralisation and addition of binding inhibitors before assay. Between-run imprecision (coefficient of variation) was 12.2 and $8.6 \%$ at 117 and $216 \mathrm{ng} / \mathrm{ml} \mathrm{IGF1}$ respectively; 8.6 and $5.2 \%$ at 3.1 and $49 \mathrm{ng} / \mathrm{ml} \mathrm{IGFBP1}$ respectively; and 16.8 and $4.4 \%$ at 540 and $4300 \mathrm{ng} / \mathrm{ml}$ IGFBP3 respectively. All assays were carried out on freshly thawed aliquots of EDTA plasma in a series of runs performed between January 2008 and February 2009.

\section{Statistical analysis}

Data were analysed with the statistical package Stata, version 10.0 (StataCorp, 2007). Continuous variables were presented as mean \pm s.E.M. and comparisons performed by Student's $t$-test. Nominal variables were presented as percentages (\%) and compared with the $\chi^{2}$-test. Logistic regression analysis was used to assess odds ratio (OR) for AAA per a 1 s.D. increase in IGF1, IGFBP1, IGFBP3 or the ratio of IGF1/IGFBP3. Linear regression analysis was used to assess associations of IGF1, IGFBP1, IGFBP3 and IGF1/IGFBP3 with abdominal aortic diameter as a continuous variable. Regression analyses were adjusted for age, body mass index, waist: hip ratio, smoking, hypertension, dyslipidemia, diabetes, CHD and serum creatinine as potential confounders. $P$ values of $<0.05$ were considered significant.

\section{Results}

\section{IGF1, IGFBP3 and IGFBPI levels in men with and without $A A A$}

After excluding men for whom suitable plasma aliquots could not be retrieved and men with incomplete data, 3981 men were included in the analysis from the cohort 
of 4263 (93.4\%). Descriptive data from this cohort have been published previously showing that IGF1 and IGFBP3 levels were negatively correlated with increasing age, while IGFBP1 levels were positively correlated (17). Physical and biochemical variables of men with and without AAA are shown in Table 1. The mean time between assessment of AAA and subsequent blood sampling was 5.73 years (median 5.76 years, range 3.26-8.22 years).

\section{Associations of IGF1, IGFBP1, IGFBP3 and IGF1/IGFBP3 with AAA}

In univariate analyses, increased IGF1, IGFBP1 and the ratio of IGF1/IGFBP3 were each associated with increased OR for AAA (Table 2). In the fully adjusted logistic regression, a 1 s.D. increase in IGF1 level was associated with OR for AAA of 1.18 (95\% confidence interval (CI) 1.05-1.33, $P=0.006)$. Exclusion of nonfasted men did not alter this result $(\mathrm{OR}=1.19,95 \% \mathrm{CI}$ 1.04-1.37, $P=0.012$ ), nor did exclusion of men with metabolic syndrome or diabetes $(\mathrm{OR}=1.25$, 95\% CI $1.08-1.44, P=0.003)$. Neither IGFBP1 nor IGFBP3 were associated with AAA in the adjusted analysis. The ratio of IGF1/IGFBP 3 remained associated with AAA in the fully adjusted model (OR $=1.22,95 \%$ CI 1.10-1.35, $P<0.001)$. Exclusion of non-fasted men did not alter this result $(\mathrm{OR}=1.26,95 \% \mathrm{CI} 1.11-1.43, \mathrm{P} \leq 0.001)$ nor did exclusion of men with metabolic syndrome or diabetes $(\mathrm{OR}=1.21$, 95\% CI 1.07-1.38, $P=0.002)$.

Distributions of AAA in each quintile of IGF1 and IGF1/IGFBP3 are shown in Table 3. In logistic regression analyses, IGF1 concentrations in the highest

Table 1 Physical and biochemical variables in community-dwelling older men compared according to the absence or presence of AAA. Continuous variables are presented as mean \pm S.E.M. and compared with the two-sample $t$-test. Nominal variables are presented as percentages and compared with the $\chi^{2}$-test.

\begin{tabular}{|c|c|c|c|}
\hline Characteristic & No AAA & AAA & $P$ value \\
\hline $\begin{array}{l}\text { Number } \\
\text { Aortic diameter (mm) } \\
\text { Age (years) } \\
\text { BMI (kg/m²) } \\
\text { WHR } \\
\text { Non smoker (\%) } \\
\text { Previous smoker (\%) } \\
\text { Current smoker (\%) } \\
\text { Hypertension (\%) } \\
\text { Dyslipidemia (\%) } \\
\text { Diabetes mellitus (\%) } \\
\text { CHD (\%) } \\
\text { Creatinine ( } \mu \text { mol/l) } \\
\text { IGF1 (ng/ml) } \\
\text { IGFBP1 (ng/ml) } \\
\text { IGFBP3 (ng/ml) } \\
\text { IGF1/IGFBP3 }\end{array}$ & $\begin{array}{l}3692 \\
21.7 \pm 0.04 \\
77.0 \pm 0.06 \\
26.5 \pm 0.06 \\
0.97 \pm 0.001 \\
35.0 \\
60.5 \\
4.6 \\
75.8 \\
74.6 \\
15.4 \\
41.0 \\
93.0 \pm 0.5 \\
140.6 \pm 1.0 \\
26.6 \pm 0.3 \\
3.791 \pm 15 \\
0.037 \pm \\
\quad 0.0002\end{array}$ & $\begin{array}{l}289 \\
36.6 \pm 0.45 \\
78.3 \pm 0.24 \\
27.2 \pm 0.22 \\
0.99 \pm 0.004 \\
11.6 \\
76.5 \\
11.9 \\
80.7 \\
86.8 \\
21.7 \\
69.2 \\
106.1 \pm 2.4 \\
152.2 \pm 3.5 \\
29.6 \pm 1.5 \\
3.705 \pm 56 \\
0.041 \pm \\
\quad 0.0007\end{array}$ & $\begin{array}{l}0.059 \\
<0.001 \\
0.004 \\
<0.001 \\
<0.001 \\
0.001 \\
0.054 \\
0.137 \\
<0.001\end{array}$ \\
\hline
\end{tabular}

WHR, waist to hip ratio; CHD, coronary heart disease. quintile compared with the lowest quintile were significantly associated with AAA $(\mathrm{OR}=1.80,95 \% \mathrm{CI}$ 1.20-2.70, $P=0.004$; Fig. 1A). Quintiles of IGFBP1 and IGFBP3 were not associated with AAA (Fig. 1B and C). Men with IGF1/IGFBP3 ratios in the highest two quintiles had increased odds of AAA compared with those in the lowest quintile (Q4 vs Q1: $\mathrm{OR}=2.90$, 95\% CI 1.82-4.63 and Q5 vs Q1: OR $=2.52$, 95\% CI 1.58-4.02, both $P<0.001$; Fig. 1D). These results were not altered by exclusion of non-fasted men nor by exclusion of men with metabolic syndrome or diabetes (data not shown).

\section{Associations of IGF1, IGFBP1, IGFBP3 and IGF1/IGFBP3 with aortic diameter}

In univariate analyses, increased IGF1, IGFBP1 and the ratio of IGF1/IGFBP3 were each associated with increased abdominal aortic diameter (Table 4). Following adjustment for all other risk factors, only IGFBP 1 and the ratio of IGF1/IGFBP 3 remained associated. The coefficient for a 1 s.D. increase in IGFBP1 was 0.227 (95\% CI 0.055-0.399, $P=0.010)$. Exclusion of non-fasted men did not alter this result $(\beta=0.275$, 95\% CI $0.079-0.471, P=0.006)$, nor did exclusion of men with metabolic syndrome or diabetes $(\beta=0.268,95 \%$ CI $0.067-0.468, P=0.009)$. For a 1 S.D. increase in IGF1/IGFBP3, the coefficient was 0.216 (95\% CI $0.063-0.368, P=0.006)$. Exclusion of nonfasted men did not alter the result $(\beta=0.214,95 \% \mathrm{CI}$ 0.037-0.392, $P=0.018$ ), nor did exclusion of men with metabolic syndrome or diabetes $(\beta=0.237,95 \%$ CI 0.066-0.409, $P=0.007)$.

\section{Multivariate models including IGF1 and IGFBP1, IGF1, and IGFBP3}

In order to assess whether the association of IGF1 with aortic diameter was influenced by IGFBP1, a multivariate model including both IGF1 and IGFBP1 and the other covariates was constructed (Table 5). In the fully adjusted model, both IGF1 and IGFBP1 were independently associated with aortic diameter (coefficient for IGF1 was $0.200,95 \%$ CI $0.43-0.357, P=0.012$, for IGFBP1 $0.274,0.098-0.449, P=0.002)$. The results were similar after log-transforming aortic diameter (data not shown).

To assess whether the association of IGF1 with aortic diameter was independent of IGFBP3, both IGF1 and IGFBP 3 were included in a multivariate model. The coefficient for IGF1 was higher compared with the adjusted model with IGF1 alone, and remained significant $(\beta=0.252,95 \%$ CI $0.063-0.442, P=0.009)$. The coefficient for IGFBP 3 was lower compared with the adjusted model with IGFBP3 alone, but the CIs did not reach statistical significance $(\beta=-0.173,95 \%$ CI -0.365 to $0.018, P=0.076)$. 
Table 2 Four separate logistic regression models evaluating the associations of IGF1, IGFBP1, IGFBP3 and the ratio of IGF1/IGFBP3 with presence of AAA in community-dwelling older men.

\begin{tabular}{|c|c|c|c|c|c|c|}
\hline & \multicolumn{3}{|c|}{ Univariate } & \multicolumn{3}{|c|}{ Adjusted $^{\mathrm{a}}$} \\
\hline & OR & $95 \% \mathrm{Cl}$ & $P$ value & OR & $95 \% \mathrm{Cl}$ & $P$ value \\
\hline IGF1 (ng/ml) & 1.19 & $1.07,1.33$ & 0.001 & 1.18 & $1.05,1.33$ & 0.006 \\
\hline IGFBP1 (ng/ml) & 1.14 & $1.02,1.27$ & 0.019 & 1.07 & $0.94,1.22$ & 0.285 \\
\hline IGFBP3 (ng/ml) & 0.91 & $0.81,1.02$ & 0.117 & 0.94 & $0.83,1.07$ & 0.363 \\
\hline IGF1/IGFBP3 & 1.25 & $1.13,1.38$ & $<0.001$ & 1.22 & $1.10,1.35$ & $<0.001$ \\
\hline
\end{tabular}

OR, odds ratio of AAA being present for a 1 s.D. increase in the variable of interest; $\mathrm{Cl}$, confidence interval.

adjusted for age, BMI, waist:hip ratio, smoking, hypertension, dyslipidemia, diabetes, coronary heart disease and serum creatinine.

\section{Sensitivity analyses}

Additional adjustment for height did not appreciably alter associations of IGF1 with AAA or aortic diameter (data not shown). Of the 289 men with AAA, 61 underwent AAA repair between 1996-1999 and 2001-2004. Excluding these men reduced statistical power, with IGF1 level no longer associated with AAA in the multivariate analysis (OR per a 1 S.D. increase $1.10,95 \%$ CI $0.96-1.26$ ). The ratio of IGF1/IGFBP3 remained associated with AAA in the adjusted analysis $(\mathrm{OR}=1.17,95 \%$ CI 1.04-1.31). In multivariate analyses, the associations of IGFBP1 and the ratio of IGF1/IGFBP3 with aortic diameter were attenuated ( $\beta=0.143,95 \%$ CI $-0.0004,0.286$ and $\beta=0.125$, $95 \%$ CI $-0.001,0.251$ respectively). When both IGF1 and IGFBP1 were included in the multivariate model, IGFBP1 remained associated with aortic diameter $(\beta=0.161,95 \%$ CI $0.015-0.308)$.

\section{Discussion}

In this study, we discovered that higher IGF1 levels or a higher ratio of IGF1/IGFBP3 were associated with increased odds of AAA. In addition, IGFBP1 was independently associated with increased aortic diameter. These findings were robust to adjustment for conventional risk factors, fasting status and prevalent metabolic syndrome or diabetes. The sensitivity analyses indicated that the ratio of IGF1/IGFBP 3 was more closely associated with AAA than IGF1.
Lower circulating IGF1 has been associated with an increased risk of heart failure and occlusive atherosclerotic disease such as stroke and CHD $(9,10,18)$. In several studies, lower IGF1 levels have also been associated with all-cause or CVD-related mortality $(19,20,21)$. AAA and atherosclerotic CVD share common risk factors such as smoking and elevated blood pressure or cholesterol levels, and often co-exist. However, AAA and CVD may develop in parallel through different pathogenic mechanisms, with weakening of the aortic wall playing a key role in aortic dilation and AAA formation (7). Changes in the walls of aneurysmal aortas are characterised by up-regulation of proteolytic pathways, the loss of matrix, inflammation and, to a variable extent, atherosclerosis (22). In a study involving 115 cases of AAA, Lindholt et al. (23) recently showed that IGF1 levels are correlated with aneurysmal diameter and rate of progression. Our study extends this observation by demonstrating that higher level of IGF 1 or the ratio of IGF1/IGFBP3 are associated with the presence of an AAA in a large cohort of community-dwelling older men.

Little is known about IGF1 activity in the walls of aortic aneurysms. A single previous study reported that IGF1 expression was reduced, while IGFBP1 and 3 concentrations were increased in aortic aneurysm tissue homogenates from ten patients who had surgery, compared with biopsies of normal aorta from ten organ donors, although it appears subjects were not matched for age and other risk factors making interpretation of this finding problematic (11). In animal models, increased IGF1 is associated with reduced degradation

Table 3 Quintile boundaries and distribution of men with AAA in each quintile of (A) IGF1 and (B) IGF1/IGFBP3. Numbers of men with AAA $(\%)$ and total number of men in each quintile are shown.

\begin{tabular}{llllll}
\hline & \multicolumn{5}{c}{ Quintile } \\
\cline { 2 - 5 } & 1 & 2 & 3 & 4 & 5 \\
\hline (A) IGF1 $(\mathrm{ng} / \mathrm{ml})$ & $1.58-94.1$ & $94.2-121$ & $122-146$ & $147-184$ & $185-738$ \\
With AAA $n(\%)$ & $44(5.56)$ & $59(7.45)$ & $47(5.99)$ & $61(7.53)$ & $78(9.81)$ \\
Total $n$ & 791 & 792 & 784 & 810 & 795 \\
(B) IGF1/IGFBP3 & $0-0.026$ & $0.027-0.032$ & $0.033-0.038$ & $0.039-0.045$ & $0.046-0.267$ \\
With AAA $n(\%)$ & $26(3.63)$ & $42(5.45)$ & $51(6.10)$ & $82(10.43)$ & $88(10.19)$ \\
Total $n$ & 716 & 770 & 836 & 786 & 864 \\
\hline
\end{tabular}



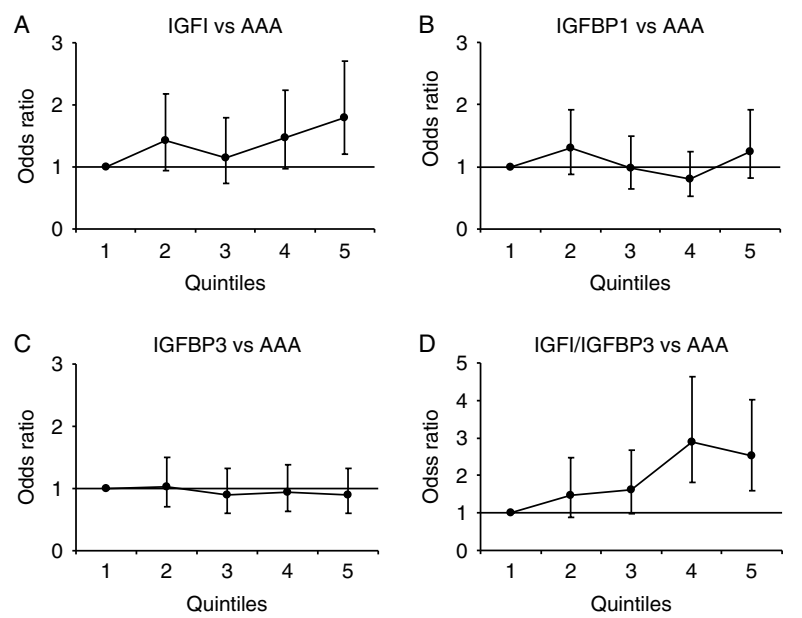

Figure 1 Logistic regression analyse evaluating the associations of IGF1, IGFBP1, IGFBP3 and the ratio of IGF1/IGFBP3 with the presence of AAA in community-dwelling older men. Odds ratios are shown for quintiles of (A) IGF1, (B) IGFBP1, (C) IGFBP3 and (D) the ratio of IGF1/IGFBP3 with the lowest quintile (Q1) as the reference. Error bars are $95 \%$ confidence intervals. Analyses were adjusted for age, body mass index, waist:hip ratio, smoking, hypertension, dyslipidemia, diabetes, coronary heart disease and serum creatinine.

of extracellular matrix and reduced expression of matrix metalloproteinases (24). IGF1 stimulates collagen synthesis (25) and facilitates wound-healing (26), mechanisms that could protect against the development of AAA. Additionally, IGF1 may exert vascular effects by stimulating growth of $\operatorname{VSMC}(27,28)$. Therefore, our results in a cohort of older men illustrate differences between animal models of AAA or acute vascular injury and repair (29), with the development of AAA in vivo. The IGF1/IGFBP system may exhibit complex effects on the vasculature, possibly via distinct actions of autocrine, paracrine and endocrine systems.

The contribution of a 1 S.D. increase in IGF1 level to the risk of having an AAA was limited with an $18 \%$ increase in risk. In older men, polymorphisms in the promoter region of the IGF1 gene are a determinant of circulating IGF1 levels distinct from GH secretion (30). Of note the association of IGF1/IGFBP3 ratio with AAA and abdominal aortic diameter analysed as a continuous variable was more prominent than that of IGF1 itself. A higher ratio of IGF1/IGFBP3 would be consistent with reduced binding of IGF1 to BP3, and a greater proportion of free or unbound IGF1 in the AAA group $(2,12)$. Thus in older men effects of the IGF1 system may be influenced by genetic factors and by IGFBP3, with higher circulating free IGF1 predisposing to aortic dilation or representing a more robust biomarker for AAA than total IGF1 levels.

Infra-renal aortic diameter is a predictor of mortality even below the threshold for diagnosis of AAA $(5,6)$. In our study, higher IGFBP1 was associated with abdominal aortic diameter and remained so after exclusion of non-fasting men, or men with metabolic syndrome or diabetes. When IGF1 and IGFBP1 were included in the multivariate model both remained associated with aortic diameter. Reduced IGFBP1 level has been associated with thickening of the carotid wall in patients with type 2 diabetes (31), and with metabolic syndrome in older men (17). Paradoxically, older adults with higher IGFBP1 levels experience increased all-cause and cardiovascular mortality despite the association of higher IGFBP1 with more favourable metabolic status $(32,33,34)$. The association of higher IGFBP1 with aortic diameter is consistent with this counterintuitive concept and IGFBP1 may act independently of IGF 1 on a cellular level to influence the vasculature (35). Additional investigation is required to assess mechanisms underlying the association of IGFBP1 with aortic diameter, and to clarify whether there is a causal relationship or whether IGFBP1 is a biomarker for adverse vascular outcomes in older men.

We have previously reported that lower free testosterone and higher LH levels were independently associated with AAA in this cohort of older men (36). This contrasts with this study where the higher IGF1 levels were associated with AAA, suggesting divergent pathways by which testosterone and IGF1 might influence AAA risk.

The strengths of this study include the large sample size, the standardised and reliable measurement of aortic diameter using ultrasound and the comprehensive adjustment for potential confounders in the multivariate analyses. Study limitations include the fact that blood testing was performed several years after baseline aortic diameter measurement. However, aortic diameter is relatively stable and the incidence of new AAA is very

Table 4 Four separate linear regression models evaluating the associations of IGF1, IGFBP1, IGFBP3 and the ratio of IGF1/IGFBP3 with abdominal aortic diameter in community-dwelling older men.

\begin{tabular}{|c|c|c|c|c|c|c|}
\hline & \multicolumn{3}{|c|}{ Univariate } & \multicolumn{3}{|c|}{ Adjusted $^{\mathrm{a}}$} \\
\hline & $\beta$ & $95 \% \mathrm{Cl}$ & $P$ value & $\beta$ & $95 \% \mathrm{Cl}$ & $P$ value \\
\hline IGF1 (ng/ml) & 0.195 & $0.039,0.351$ & 0.014 & 0.152 & $-0.002,0.305$ & 0.053 \\
\hline IGFBP1 (ng/ml) & 0.266 & $0.111,0.422$ & 0.001 & 0.227 & $0.055,0.399$ & 0.010 \\
\hline IGFBP3 (ng/ml) & -0.116 & $-0.272,0.040$ & 0.146 & -0.026 & $-0.181,0.129$ & 0.743 \\
\hline IGF1/IGFBP3 & 0.329 & $0.173,0.485$ & $<0.001$ & 0.216 & $0.063,0.368$ & 0.006 \\
\hline
\end{tabular}

$\beta$, Regression coefficient per 1 S.D. increase in the variable of interest; Cl, confidence interval.

${ }^{a}$ Adjusted for age, BMI, waist:hip ratio, smoking, hypertension, dyslipidemia, diabetes, coronary heart disease and serum creatinine. 
Table 5 Multivariate linear regression model evaluating associations of IGF1 and IGFBP1 with abdominal aortic diameter in community-dwelling older men. All covariates shown were included in the model and analysed according to a 1 S.D. increase for continuous variables, or the presence of a dichotomous risk factor.

\begin{tabular}{lrrr}
\hline & \multicolumn{1}{c}{$\boldsymbol{\beta}$} & \multicolumn{1}{c}{$\mathbf{9 5 \%} \mathbf{~ C l}$} & $\boldsymbol{P}$ value \\
\hline IGF1 $(\mathrm{ng} / \mathrm{ml})$ & 0.200 & $0.043,0.357$ & 0.012 \\
IGFBP1 $(\mathrm{ng} / \mathrm{ml})$ & 0.274 & $0.098,0.449$ & 0.002 \\
Age $(\mathrm{years})$ & 0.150 & $0.107,0.194$ & $<0.001$ \\
BMI $\left(\mathrm{kg} / \mathrm{m}^{2}\right)$ & 0.128 & $0.073,0.182$ & $<0.001$ \\
WHR & 2.571 & $-0.094,5.238$ & 0.059 \\
Previous smoker & 0.886 & $0.559,1.213$ & $<0.001$ \\
Current smoker & 2.980 & $2.266,3.695$ & $<0.001$ \\
Hypertension & -0.026 & $-0.386,0.335$ & 0.889 \\
Dyslipidemia & 0.220 & $-0.139,0.579$ & 0.229 \\
Diabetes mellitus & 0.013 & $-0.412,0.439$ & 0.951 \\
CHD & 0.954 & $0.637,1.271$ & $<0.001$ \\
Creatinine ( $\mu$ mol/l) & 0.013 & $0.008,0.018$ & $<0.001$ \\
\hline
\end{tabular}

$\beta$, regression coefficient; $\mathrm{Cl}$, confidence interval; WHR, waist to hip ratio; $\mathrm{CHD}$, known coronary heart disease.

low ( $\sim 0.4 \%$ pa) $(37)$, therefore the small number of interval cases of AAA is unlikely to have influenced the results. We did not have serial assessments of aortic diameter or blood samples for analysis, which restricts our ability to assess direction of causality. The cohort comprised men who returned for assessment and blood sampling from an earlier population-based sample (13). Therefore a 'healthy survivor' effect is possible which would make our results more conservative and applicable to generally healthier community-dwelling older men, and we cannot comment on associations in women. We did not have the capacity to measure free or unbound IGF1 levels either by immunoassay or ultracentrifugation, nor were we able to measure circulating IGF1 bioactivity (20). Therefore, our assessment was limited to circulating total IGF1, IGFBP1 and IGFBP3.

In conclusion, this study shows a positive association between circulating IGF1 or the ratio of IGF1/IGFBP3 with AAA, while IGFBP1 is independently associated with aortic dilation. IGF1 may have adverse effects in the aorta during ageing. If further studies replicate this observation, pre-clinical models may be required to assess the mechanistic basis for these associations.

\section{Declaration of interest}

The authors declare that there is no conflict of interest that could be perceived as prejudicing the impartiality of the research reported.

\section{Funding}

This work was supported by the National Health and Medical Research Council of Australia (NHMRC) Project Grants 279408, 379600, 403963 and 513823. B B Yeap received a Clinical Investigator Award from the Sylvia and Charles Viertel Charitable Foundation, New South Wales, Australia. J Golledge is supported by funding from NHMRC and the Queensland Government. P E Norman is supported by NHMRC Practitioner Fellowship 458505.

\section{Acknowledgements}

The authors thank Sylvia Johnson of DSL Australia, and staff of Fremantle Hospital for assistance with the assays, management and staff of Shenton Park Hospital, and all the participants in the Western Australian Abdominal Aortic Aneurysm Programme and the Health In Men Study. We acknowledge assistance received from the Data Linkage Unit of the Health Department of Western Australia.

\section{References}

1 Sherlock M \& Toogood AA. Aging and the growth hormone/insulin like growth factor-I axis. Pituitary 200710 189-203. (doi:10. 1007/s11102-007-0039-5)

2 Ohlsson C, Mohan S, Sjogren K, Tivesten A, Isgaard J, Isaksson O, Jansson J-O \& Svensson J. The role of liver-derived insulin-like growth factor-I. Endocrine Reviews 200930 494-535. (doi:10. 1210/er.2009-0010)

3 Juul A. Serum levels of insulin-like growth factor I and its binding proteins in health and disease. Growth Hormone and IGF Research 200313 113-170. (doi:10.1016/S1096-6374(03)00038-8)

4 Kotronen A, Lewitt M, Hall K, Brismar K \& Yki-Jarvinen H. Insulin-like growth factor binding protein 1 as a novel specific marker of hepatic insulin sensitivity. Journal of Clinical Endocrinology and Metabolism 200893 4867-4872. (doi:10.1210/jc. 2008-1245)

5 Norman P, Le M, Pearce C \& Jamrozik K. Infrarenal aortic diameter predicts all-cause mortality. Arteriosclerosis, Thrombosis, and Vascular Biology 200424 1278-1282. (doi:10.1161/01.ATV. $0000131261.12051 .7 \mathrm{f})$

6 Freiberg MS, Arnold AM, Newman AB, Edwards MS, Kraemer KL \& Kuller LH. Abdominal aortic aneurysms, increasing infrarenal aortic diameter, and risk of total mortality and incident cardiovascular disease events. Circulation $2008 \quad 117$ 1010-1017. (doi:10.1161/CIRCULATIONAHA.107.720219)

7 Johnsen SH, Forsdahl S, Singh K \& Jacobsen BK. Atherosclerosis in abdominal aortic aneurysms: a causal event of a process running in parallel? The Tromso Study. Arteriosclerosis, Thrombosis, and Vascular Biology 201030 1263-1268. (doi:10.1161/ATVBAHA. 110.203588

8 Grant MB, Wargovich TJ, Ellis EA, Tarnuzzer R, Caballero S, Estes K, Rossing M, Spoerri PE \& Pepine C. Expression of IGF-I, IGF-I receptor and IGF binding proteins $-1,-2,-3,-4$ and -5 in human atherectomy specimens. Regulatory Peptides 199667 137-144. (doi:10.1016/S0167-0115(96)00124-3)

9 Juul A, Scheike T, Davidsen M, Gyllenborg J \& Jorgensen T. Low serum insulin-like growth factor 1 is associated with increased risk of ischemic heart disease. A population-based case-control study. Circulation 2002106 939-944. (doi:10.1161/01.CIR.00000 27563.44593.CC)

10 Johnsen SP, Hundborg HH, Sorensen HT, Orskov H, Tjonneland A, Overvad K \& Jorgensen JO. Insulin-like growth factor (IGF) I, -II and IGF binding protein-3 and risk of ischemic stroke. Journal of Clinical Endocrinology and Metabolism 200590 5937-5941. (doi:10.1210/jc.2004-2088)

11 Panek B, Gacko M \& Palka J. Metalloproteinases, insulin-like growth factor-I and its binding proteins in aortic aneurysm. International Journal of Experimental Pathology 2004 85 159-164. (doi:10.1111/j.0959-9673.2004.00386.x)

12 Sierra-Johnson J, Romero-Corral A, Somers VK, Lopez-Jimenez F, Malarstig A, Brismar K, Hamsten A, Fisher RM \& Hellenius M-L. IGF-I/IGFBP-3 ratio: a mechanistic insight into the metabolic syndrome. Clinical Science 2009116 507-512. (doi:10.1042/ CS20080382)

13 Norman PE, Flicker L, Almeida OP, Hankey GJ, Hyde Z \& Jamrozik K. Cohort profile: the Health In Men Study (HIMS). International Journal of Epidemiology 200938 48-52. (doi:10. 1093/ije/dyn041) 
14 Holman CD, Bass AJ, Rouse IL \& Hobbs MS. Population-based linkage of health records in Western Australia: development of a health services research linked database. Australian and New Zealand Journal of Public Health 199923 453-459. (doi:10.1111/j. 1467-842X.1999.tb01297.x)

15 Norman P, Spencer CA, Lawrence-Brown MM \& Jamrozik K. C-reactive protein levels and the expansion of screen-detected abdominal aortic aneurysms in men. Circulation $2004 \mathbf{1 1 0}$ 862-866. (doi:10.1161/01.CIR.0000138746.14425.00)

16 Wilmink A, Hubbard C, Day N \& Quick C. The incidence of small abdominal aortic aneurysms and the change in normal infrarenal aortic diameter: implications for screening. European Journal of Vascular and Endovascular Surgery 200121 165-170. (doi:10. 1053/ejvs.2000.1285)

17 Yeap BB, Chubb SAP, Ho KKY, Setoh JWS, McCaul KA, Norman PE, Jamrozik K \& Flicker L. Insulin-like growth factor-I and its binding proteins 3 and 1 are differentially associated with metabolic syndrome in older men. European Journal of Endocrinology 2010162 249-257. (doi:10.1530/EJE-09-0852)

18 Vasan RS, Sullivan LM, D'Agostino RB, Roubenoff R, Harris T, Sawyer DB, Levy D \& Wilson PW. Serum insulin-like growth factor 1 and risk for heart failure in elderly individuals without a previous myocardial infarction: the Framingham Heart Study. Annals of Internal Medicine $2003139642-648$.

19 Laughlin GA, Barrett-Connor E, Criqui MH \& Kritz-Silverstein D. The prospective association of serum insulin-like growth factor I (IGF-I) and IGF-binding protein-1 levels with all cause and cardiovascular mortality in older adults: the Rancho Bernardo study. Journal of Clinical Endocrinology and Metabolism $2004 \mathbf{8 9}$ 114-120. (doi:10.1210/jc.2003-030967)

20 Brugts MP, van den Beld AW, Hofland LJ, van der Wansem K, van Koetsveld PM, Frystyk J, Lamberts SWJ \& Janssen JAMJL. Low circulating insulin-like growth factor I bioactivity in elderly men is associated with increased mortality. Journal of Clinical Endocrinology and Metabolism 200893 2515-2522. (doi:10. 1210/jc.2007-1633)

21 Van Bunderen CC, van Nieuwpoort IC, van Schoor NM, Deeg DJH, Lips P \& Drent ML. The association of serum insulin-like growth factor-I with mortality, cardiovascular disease, and cancer in the elderly: a population-based study. Journal of Clinical Endocrinology and Metabolism 201095 4616-4624. (doi:10.1210/jc.20100940)

22 Golledge J, Muller J, Daugherty A \& Norman PE. Abdominal aortic aneurysm: pathogenesis and implications for management. Arteriosclerosis, Thrombosis, and Vascular Biology $2006 \mathbf{2 6}$ 2605-2613. (doi:10.1161/01.ATV.0000245819.32762.cb)

23 Lindholt JS, Martin-Ventura JL, Urbonavicius S, Ramos-Mozo P, Flyvbjerg A, Egido J, Henneberg EW \& Frystyk J. Insulin-like growth factor I - a novel biomarker of abdominal aortic aneurysms. European Journal of Vascular and Endovascular Surgery 201142 560-562. (doi:10.1016/j.ejvs.2011.07.013)

24 Yamawaki-Ogata A, Hashizume R, Satake M, Kaneko H, Mizutani S, Moritan T, Ueda Y \& Narita Y. A doxycycline loaded, controlled-release, biodegradable fiber for the treatment of aortic aneurysms. Biomaterials 201031 9554-9564. (doi:10.1016/j. biomaterials.2010.08.069)

25 Etheredge L, Kane BP, Valkov N, Adams S, Birk DE \& Hassell JR. Enhanced cell accumulation and collagen processing by keratocytes cultured under agarose and in media containing IGF-I, TGF$\beta$ or PDGF. Matrix Biology 201029 519-524. (doi:10.1016/j. matbio.2010.05.003)

26 Jeschke MG, Schubert T, Krickhahn M, Polykandriotis E, Klein D, Perez-Polo JR, Przkora R \& Herndon DN. Interaction of exogenous liposomal insulin-like growth factor-I cDNA gene transfer with growth factors on collagen expression in acute wounds. Wound Repair and Regeneration 200513 269-277. (doi:10.1111/j.10671927.2005.130309.x)

27 Delafontaine P, Song Y-H \& Li Y. Expression, regulation, and function of IGF-1, IGF-1R, and IGF-1 binding proteins in blood vessels. Arteriosclerosis, Thrombosis, and Vascular Biology 200424 435-444. (doi:10.1161/01.ATV.0000105902.89459.09)

28 Conti E, Musumeci MB, De Giusti M, Dito E, Mastromarino V, Autore C \& Volpe M. IGF-I and atherothrombosis: relevance to pathophysiology and therapy. Clinical Science $2011120377-402$. (doi:10.1042/CS20100400)

29 Allaire E, Muscatelli-Groux B, Guinault A-M, Pages C, Goussard A, Mandet C, Bruneval P, Melliere D \& Becquemin J-P. Vascular smooth muscle cell endovascular therapy stabilizes already developed aneurysms in a model of aortic injury elicited by inflammation and proteolysis. Annals of Surgery 2004239 417-427. (doi:10.1097/01.sla.0000114131.79899.82)

30 Rietveld I, Janssen JA, van Rossum EF, Houwing-Duistermaat JJ, Rivadeneira F, Hofman A, Pols HA, van Duijn CM \& Lamberts SW. A polymorphic CA repeat in the IGF-I gene is associated with gender-specific differences in body height, but has no effect on the secular trend in body height. Clinical Endocrinology 200461 195-203. (doi:10.1111/j.1365-2265.2004.02078.x)

31 Leinonen ES, Salonen JT, Salonen RM, Koistinen RA, Leinonen PJ, Sarna SS \& Taskinen M-R. Reduced IGFBP-1 is associated with thickening of the carotid wall in type 2 diabetes. Diabetes Care 200225 1807-1812. (doi:10.2337/diacare.25.10.1807)

32 Harrela M, Qiao Q, Koistinen R, Tuomilehto J, Nissinen A, Seppala M \& Leinonen P. High serum insulin-like growth factor binding protein-1 is associated with increased cardiovascular mortality in elderly men. Hormone and Metabolic Research 200234 144-149. (doi:10.1055/s-2002-23198)

$33 \mathrm{Hu}$ D, Pawlikowska L, Kanaya A, Hsueh W-C, Colbert L, Newman AB, Satterfield S, Rosen C, Cummings SR, Harris TB \& Ziv E. Serum insulin-like growth factor- 1 binding proteins 1 and 2 and mortality in older adults: the health, aging, and body composition study. Journal of the American Geriatrics Society 2009 57 1213-1218. (doi:10.1111/j.1532-5415.2009.02318.x)

34 Yeap BB, Chubb SAP, McCaul KA, Ho KKY, Hankey GJ, Norman PE \& Flicker L. Associations of insulin-like growth factor-I and its binding proteins 1 and 3 with all-cause and cardiovascular mortality in older men. The Health In Men Study. European Journal of Endocrinology 2011 164 715-723. (doi:10.1530/EJE11-0059)

35 Wheatcroft SB \& Kearney MT. IGF-dependent and IGF-independent actions of IGF-binding protein-1 and -2: implications for metabolic homeostasis. Trends in Endocrinology and Metabolism 200920 153-162. (doi:10.1016/j.tem.2009.01.002)

36 Yeap BB, Hyde Z, Norman PE, Chubb SAP \& Golledge J. Associations of total testosterone, sex hormone-binding globulin, calculated free testosterone, and luteinising hormone with prevalence of abdominal aortic aneurysm in older men. Journal of Clinical Endocrinology and Metabolism $2010 \quad 95$ 1123-1130. (doi:10.1210/jc.2009-1696)

37 Forsdahl SH, Singh K, Solberg S \& Jacobsen BK. Risk factors for abdominal aortic aneurysms. A 7-year prospective study: the Tromso Study, 1994-2001. Circulation 2009119 2201-2208. (doi:10.1161/CIRCULATIONAHA.108.817619)

Received 17 August 2011

Revised version received 21 November 2011

Accepted 23 November 2011 